Tropical Journal of Pharmaceutical Research March 2016; 15 (3): 447-451

ISSN: $1596-5996$ (print); 1596-9827 (electronic)

(C) Pharmacotherapy Group, Faculty of Pharmacy, University of Benin, Benin City, 300001 Nigeria.

All rights reserved.

Available online at http://www.tjpr.org

Original Research Article

http://dx.doi.org/10.4314/tjpr.v15i3.3

\title{
Oral Mucoadhesive Buccal Film of Ciprofloxacin for Periodontitis: Preparation and Characterization
}

\author{
Wan Wu ${ }^{1}$, Wei Chen ${ }^{2}$ and Qiong Jin $^{2 \star}$ \\ ${ }^{1}$ Department of Implantation, The First Affiliated Hospital of Wenzhou Medical University, ${ }^{2}$ Department of Stomatology, School \\ and Hospital of Stomatology, Wenzhou Medical University. Wenzhou 32500, PR China
}

*For correspondence: Email: asdjinqiong@hotmail.com; Tel/Fax: 0086-577-88855488

Revised accepted: 5 February 2016

\begin{abstract}
Purpose: To prepare and characterise ciprofloxacin mucoadhesive buccal films for localised, improved drug delivery in periodontitis.

Methods: Ciprofloxacin-loaded buccal films containing $50 \mathrm{mg}$ ciprofloxacin were prepared mucoadhesive polymers sodium cellulose (SCMC) and sodium alginate, using a solvent evaporation method. The films were evaluated in terms of thickness, weight, folding endurance, surface $\mathrm{pH}$, drug content, swelling, mucoadhesive properties, release characteristics, and in vivo anti-periodontitis activity, using ampicillin as the standard.

Results: The buccal films showed good drug loading $(94.50 \pm 0.04$ to $99.69 \pm 0.21 \%)$ and significant mucoadhesion in terms of in vitro residence time, as well as significant swelling (38.20 \pm 1.62 to $54.42 \pm$ $2.32 \%)$. In addition to the good physicochemical properties of the films, ex vivo drug release was high (83.22 \pm 1.42 to $90.24 \pm 2.01$ after $12 \mathrm{~h}$. The films displayed potent anti-periodontitis activity, as indicated by a significant reduction in the bacterial count in a periodontitis model. The samples treated with BFC4 formulation (containing 3:1 SCMC and sodium alginate) exhibited the lowest growth of colonies (57 $\pm 2.02 \mathrm{CFU} / \mathrm{mL}$ ) compared with those treated with the BFC3 formulation (69 \pm 2.41 $\mathrm{CFU} / \mathrm{mL})$ and the standard $(80 \pm 5.22 \mathrm{CFU} / \mathrm{mL})$.

Conclusion: Formulation BFC4 has suitable physicochemical, drug-release, and anti-periodontitis activity for buccal administration.
\end{abstract}

Keywords: Periodontitis, Ciprofloxacin, Buccal film, Mucoadhesive, Periodontitis, Sodium carboxymethyl cellulose, Sodium alginate

Tropical Journal of Pharmaceutical Research is indexed by Science Citation Index (SciSearch), Scopus, International Pharmaceutical Abstract, Chemical Abstracts, Embase, Index Copernicus, EBSCO, African Index Medicus, JournalSeek, Journal Citation Reports/Science Edition, Directory of Open Access Journals (DOAJ), African Journal Online, Bioline International, Open-J-Gate and Pharmacy Abstracts

\section{INTRODUCTION}

Drug delivery via an oral route is preferred for the treatment of a variety of local and systemic diseases. Periodontitis is an inflammatory disease of the gums that damages the soft tissues and bones that support the teeth. Periodontitis is caused by pathogens such as Porphyromonas gingivalis, Prevotella intermedia, and Aggregatibacter (Actinobacillus) actinomycetemcomitans. The treatment of periodontitis includes the suppression and elimination of subgingival periodontal pathogens, which require sustained delivery of antibacterial agents [1-4].

Oral controlled delivery can be achieved using a number of drug delivery systems, including strips, gels, films, and implants [5-9]. Additional synergistic effects can be achieved the strategy of mucoadhesion, which prolongs the residence time of the dosage form at the site of absorption and facilitates intimate contact between the 
dosage form and underlying absorption surface to improve and enhance the bioavailability of drugs.

Ciprofloxacin hydrochloride is a secondgeneration fluoroquinolone is an antibiotic that is against a wide range of Gram-negative and Gpositive facultative bacteria, including periodontal pathogens. It has a biological half-life of $3 \sim 4 \mathrm{~h}$, thus requiring frequent dosing [10-12].

Mucoadhesive buccal films can be used to overcome this problem $[6,8,13]$. Therefore, ciprofloxacin mucoadhesive buccal films were formulated using sodium carboxymethyl cellulose (SCMC) and sodium alginate polymers. In microspheres, these mucoadhesive polymers prolong the residence time of the dosage form in the gastrointestinal tract and are more suitable as matrix material for oral controlled release.

The films were evaluated in terms of their thickness, weight, folding endurance, surface $\mathrm{pH}$, drug content, swelling, mucoadhesive properties, release characteristics and in vivo antiperiodontitis activity.

\section{EXPERIMENTAL}

\section{Materials}

Ciprofloxacin hydrochloride, sodium carboxymethyl cellulose high-viscosity grade, and sodium alginate were purchased from Sigma Aldrich, USA. All other reagents used were of analytical grade.

\section{Preparation of mucoadhesive buccal film of ciprofloxacin}

The ciprofloxacin prepared using a solventcasting method [13,14]. SCMC and sodium alginate were used as mucoadhesive polymers. A certain amount of polymer was dissolved in 20 $\mathrm{mL}$ distilled water, and $250 \mathrm{mg}$ ciprofloxacin hydrochloride was added to this solution with continuous stirring, until a homogeneous solution formed. The desired quantity $(2 \% \mathrm{w} / \mathrm{v})$ of glycerol was added to the homogenised drug polymer solution as a plasticiser. Then, the polymer solution was transferred to a previously prepared glass block and kept at room temperature for drying. The dried film was cut to the desired size, wrapped in aluminium foil, and kept in a desiccator until used.

\section{Evaluation of the physicochemical properties}

For prepared films, we evaluated the weight (a 2 $\times 2 \mathrm{~cm}$ piece using a digital balance), thickness (using a micrometre screw gauge), surface $\mathrm{pH}$ (after $4 \mathrm{~h}$ on an agar plate in an incubator maintained at $37 \pm 0.2^{\circ} \mathrm{C}$ ), swelling percentage (expressed in terms of the increase in film weight after $2 \mathrm{~h}$ on an agar plate at $37 \pm 0.2^{\circ} \mathrm{C}$ ), folding endurance (number of times a small strip of film could be folded at the same place before breaking), and drug content (a film was dissolved in $100 \mathrm{~mL}$ methanol, stirred for $4 \mathrm{~h}$, and then quantified at $272 \mathrm{~nm}$ in a ultraviolet (UV) spectrophotometer) $(n=3)[13,14]$.

\section{Determination of the in vitro residence time}

The in vitro residence time was determined using an USP disintegration apparatus, as reported. This method records the time required for complete erosion or dislodgement of the film from the mucosal surface (segments of porcine buccal mucosa glued on a glass slab and placed in a moving disintegration apparatus in phosphate buffer (PB) at $\mathrm{pH} 6.6$ and $37 \pm 2{ }^{\circ} \mathrm{C}$ ) $(n=3)$.

\section{Ex vivo permeation studies}

Ex vivo permeation studies of ciprofloxacin mucoadhesive buccal films were conducted in a modified Franz diffusion cell using an excised layer of porcine buccal mucosa. The medium (15 $\mathrm{mL} \mathrm{PB}$ at $\mathrm{pH} 7.4$ ) in the receptor compartment was stirred with a magnetic stirrer (at $400 \mathrm{rpm}$ ) maintaining a temperature of $37 \pm 1^{\circ} \mathrm{C}$. Samples were withdrawn at different times up to $12 \mathrm{~h}$ and analysed spectrophotometrically.

\section{Assessment of in vivo anti-periodontitis activity}

Adult Wistar rats with a mean weight of $180-200$ $\mathrm{g}$ were acclimatised for 1 week before the experiment. Five rats were housed per group at a temperature of $23 \pm 1{ }^{\circ} \mathrm{C}$ and relative humidity of $60 \pm 5 \%$ with free access to water and food.

Table 1: Composition mucoadhesive buccal

\begin{tabular}{lccrrr}
\hline Ingredient (g) & BFC1 & BFC2 & BFC3 & BFC4 & BFC5 \\
\hline Ciprofloxacin HCl & 0.50 & 0.50 & 0.50 & 0.50 & 0.50 \\
Sodium carboxymethyl cellulose & 1.0 & - & 0.50 & 0.75 & 0.25 \\
Sodium alginate & - & 1.0 & 0.50 & 0.25 & 0.75 \\
\hline
\end{tabular}


General anaesthesia was obtained by intramuscular injection of a solution of ketamine $10 \%$ and xylazine $2 \%(2: 1)$ at $0.12 \mathrm{~mL} / 100 \mathrm{~g}$ body weight. The animals were kept on an operating table, with their mouths opened to access the teeth. Ligatures of non-absorbable sterile silk thread were tied around the lower incisors in a figure "8". The ligature was left in place for 14 days as a gingival irritant and resulted in the development of plaque and periodontitis. The animals were kept in a uniform environment for 14 days and were checked daily to evaluate the suture, food and water intake, and body weight $[15,16]$.

The test group with induced periodontitis was treated with buccal films of ciprofloxacin (BFC4 and BFC3 formulations), the standard group was treated with ampicillin (1.0 mg/disc), and the control group was treated with blank film. The agar well-diffusion method was used to determine the anti-periodontitis activity. The gingiva was swabbed with sterile cotton swabs, which were then swabbed on nutrient agar and potato dextrose agar plates, and the microbial growth was determined after 2 days.

\section{Statistical analysis}

The results are expressed as means \pm standard deviation. The statistical analysis was performed using Origin 9 (USA). The groups were compared using one-way analysis of variance. $P$ $<0.05$ was considered statistically significant.

\section{RESULTS}

Mucoadhesive buccal films of ciprofloxacin hydrochloride were prepared using SCMC and gelatin by a solvent casting method. Buccal films containing different proportions of the polymers were generated (Table 1). The physicochemical properties of the films were evaluated, including the thickness, weight, folding endurance, surface $\mathrm{pH}$, drug content, swelling percentage, in vitro residence time, and mucoadhesive properties (Table 2).

The film thicknesses ranged from $0.21 \pm 0.12$ to $0.29 \pm 0.030 \mathrm{~mm}$, the weight ranged from $120 \pm$ 2.04 to $170 \pm 2.02 \mathrm{mg}$, and the surface $\mathrm{pH}$ ranged from $6.24 \pm 0.02$ to $6.67 \pm 0.01$. All of the films had good folding endurance, and none showed any cracks below 290. The films showed good swelling in the swelling study. The swelling percentage of the films ranged from $38.20 \pm 1.62$ to $54.42 \pm 2.32 \%$ in the following order of formulations: BFC4 > BFC3 > BFC5 > BFC1 > $\mathrm{BFC2}$. The in vitro residence time ranged from $3.35 \pm 0.224$ to $4.05 \pm 0.072 \mathrm{~h}$. The drug content was very good for all formulations (94.50 \pm 0.04 to $99.69 \pm 0.21 \%$ ).

Table 2: Physical characteristics of the ciprofloxacin mucoadhesive buccal films $(n=3)$

\begin{tabular}{|c|c|c|c|c|c|c|}
\hline $\begin{array}{l}\text { Buccal } \\
\text { film }\end{array}$ & $\begin{array}{c}\text { Thickness } \\
(\mathrm{mm})\end{array}$ & Surface pH & $\begin{array}{c}\text { Swelling (\%, } \\
\text { 3h) }\end{array}$ & $\begin{array}{c}\text { In vitro } \\
\text { residence time } \\
\text { (h) }\end{array}$ & $\begin{array}{l}\text { Folding } \\
\text { endurance }\end{array}$ & $\begin{array}{c}\text { Drug content } \\
(\%)\end{array}$ \\
\hline$\overline{B E C 1}$ & $0.21 \pm 0.12^{*}$ & & $41.21 \pm 1.92$ & $3.55 \pm 0.240^{*}$ & & \\
\hline & $0.22 \pm 0.086$ & & $38.20 \pm 1.62$ & $3.35 \pm 0.224^{*}$ & & $99.69 \pm 0.21^{*}$ \\
\hline & $0.25 \pm 0.080^{*}$ & $6.41 \pm 0.02^{*}$ & $51.09 \pm 1.25^{\star}$ & $3.75 \pm 0.280^{*}$ & $290.60 \pm 19.09^{*}$ & $96.24 \pm 0.12^{*}$ \\
\hline & $0.29 \pm 0.030^{*}$ & $6.67 \pm 0.01$ & $54.42 \pm 2.32^{\star}$ & $4.05 \pm 0.072^{*}$ & $295.30 \pm 8.08^{\star}$ & $96.40 \pm 0.01$ \\
\hline & $0.28 \pm 0.12^{\star}$ & $6.52 \pm 0.02^{*}$ & $49.24 \pm 2.12^{*}$ & $3.65 \pm 0.020^{*}$ & $290.90 \pm 9.80^{*}$ & $94.50 \pm 0.04^{*}$ \\
\hline
\end{tabular}

${ }^{*} P<0.05$

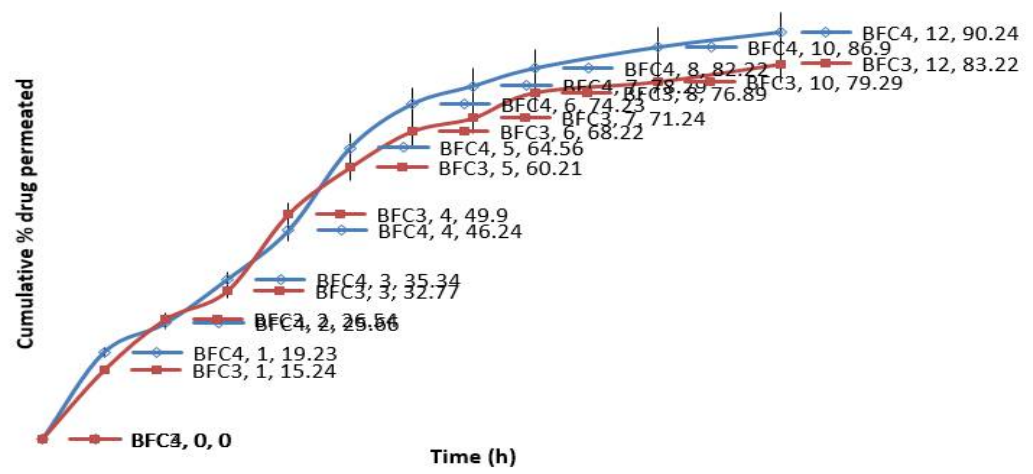

Figure 1: Ex vivo permeation studies of selected $\mathrm{CH}$ mucoadhesive buccal films. Permeation studies of formulations BFC3 $(\square)$, containing SCMC and sodium alginate $(1: 1)$, and BFC4 $(\Delta)$, containing SCMC and sodium alginate (3:1), in $\mathrm{PB}$ at $\mathrm{pH} 7.4$ 
An ex vivo permeation study was performed for formulations BFC3 and BFC4, which had good physicochemical properties (including a high drug content, swelling percentage, and in vitro residence time). The drug release was significantly higher for BFC4 (90.24 $\pm 2.01 \%)$ than for BFC3 $(83.22 \pm 1.42 \%)$ at the end of the $12 \mathrm{~h}$ ex vivo permeation study (Fig. 1).

The CFU/mL was reduced significantly for the samples cultured with the test groups compared with the control and standard (Table 2). The BFC4-treated samples had the lowest CFU (57 \pm 2.02 $\mathrm{CFU} / \mathrm{mL}$ ) compared with BFC3-treated samples $(69 \pm 2.41 \mathrm{CFU} / \mathrm{mL})$ and the standard $(80 \pm 5.22 \mathrm{CFU} / \mathrm{mL})$.

Table 3: In vivo periodontitis activity

\begin{tabular}{ll}
\hline Swab sample & $\mathrm{CFU} / \mathrm{mL}^{*}$ \\
\hline Control & $250 \pm 8.24$ \\
Ampicillin (standard) & $80 \pm 5.22$ \\
BFC3 (test film) & $69 \pm 2.41$ \\
BFC4 (test film) & $57 \pm 2.02$
\end{tabular}

*Samples were incubated for $48 h$, and CFUs were counted

\section{DISCUSSION}

An acidic or alkaline $\mathrm{pH}$ may irritate the buccal mucosa and affect the degree of polymer hydration. Therefore, the surface $\mathrm{pH}$ of the buccal films was selected to optimise both drug permeation and mucoadhesion $[13,14]$. Attempts were made to keep the surface $\mathrm{pH}$ as close to buccal/salivary $\mathrm{pH}$ as possible. The surface $\mathrm{pH}$ of all films was the salivary $\mathrm{pH}$.

The effect of swelling behaviour on the residence time of ciprofloxacin hydrochloride on films prepared from various mucoadhesive polymers was also observed The comparative swelling of various formulations was in the order BFC4 > BFC3 > BFC5 > BFC1 > BFC2. Swelling has been reported to have a significant effect on the residence time of buccal films $[13,14]$. In a recent study, the swelling of HEC films was reduced by the addition of Carbopol 934P and EudragitRL100, but was increased by the addition of SCMC in verapamil hydrochloride buccal films [17]. In general, the films with the highest degree of swelling had greater residence times, while the films with the least swelling had shorter residence times. Formulation BFC3 (prepared with sodium alginate) had the least swelling and the shortest residence time.

The ex vivo permeation was also reported to be good for SCMC-like polymers. Semalty et al reported greater drug permeation with SCMC- containing buccal film [13]. Note that the water solubility profiles of the drug evaluated in that study (diltiazem $\mathrm{HCl}$ ) and ciprofloxacin $\mathrm{HCl}$ are similar. Thus, their results support the percentage of drug permeation.

The ex vivo release characteristics and in vivo anti periodontitis activity indicated that BFC3 and BFC4 were very effective for treating periodontitis. BFC4 showed better release and better anti-periodontitis activity. The antiperiodontitis activity of both films was better than that of the standard (ampicillin).

Studies have reported the anti-periodontitis activity of films or other localised oral mucosal or gingival drug delivery systems [18-23]. Many studies have reported on the potential of novel ciprofloxacin delivery devices in the treatment of periodontitis [24-27]. Among these studies, films showed promising results.

\section{CONCLUSION}

Mucoadhesive buccal films of ciprofloxacin hydrochloride prepared using mucoadhesive polymers had satisfactory physicochemical properties, good drug-loading and mucoadhesive properties, and high ex vivo permeation and antiperiodontitis activity. Buccal film formulation BFC4 (containing SCMC and sodium alginate in a 3:1 ratio) had the best physicochemical, drugrelease, and anti-periodontitis activity.

\section{REFERENCES}

1. Drisko $\mathrm{CH}$. Nonsurgical periodontal therapy. Periodontol. 2001; 25:7788.

2. Bosshardt $D D$, Stadlinger B, Terheyden H. Cell-to-cell communication-periodontal regeneration. Clin Oral Implants Res. 2015; 26(3):229239.

3. Koll-Klais P, Mandar R, Leibur E, Mikelsaar M. Oral microbial ecology in chronic periodontitis and periodontal health. Microbial Eco Health Disease. 2005; 17:146155

4. Mummolo S, D'Ercole S, Marchetti E, Campanella V, Martinelli D, Marzo G, Tripodi D. Oral antiseptic and periodontitis: a clinical and microbiological study. Oral Health Dent Manag. 2014; 13(3):698702.

5. Sitzman C. Evaluation of a hydrophilic gingival dental sealant in beagle dogs. J Vet Dent. 2013; 30(3):150155.

6. Agarwal S, Venkatesh M, Udupa N. Controlled drug delivery systems for periodontitis. Pharm Review. 2004; 8: 6182.

7. Soskolone WA, Friedman M, Intra-periodontal pocket drug delivery systems. Ed by Michael J Rathbone, In: Oral delivery, vol. 74, Marcel Dekker, 2004; chapter 14, pp. 359379. 
8. Venkateshwari $Y$, Jayachandra RB, Sampath Kumar $D$, Mittal N, Pandit JK. Development of low-cost tetracycline strip for long-term treatment of periodontal disease. Indian Drugs. 1995; 32:205-209.

9. Samaranayake L, Ferguson M. Delivery of antifungal agents to the oral cavity, Adv. Drug Del. Rev. 1994; 13:161179.

10. Upadhye K, Bakhle S, Dixit G, Wadetwar R, Deshpande $S$, Nagulwar $V$. Preparation and evaluation of gelatin microspheres containing ciprofloxacin hydrochloride, Indian Drugs 2004; 41(11):665669.

11. Semalty A, Semalty M. Preparation and characterization of mucoadhesive microspheres of ciprofloxacin hydrochloride, Indian Drugs. 2007; 44(5):368372.

12. Tezel A, Yucel O, Orbak R, Kara C, Kavrut F, Yagiz $H$, Sahin $T$. The gingival crevicular fluid ciprofloxacin level in subjects with gingivitis and periodontitis, and its effects on clinical parameters. J Periodontal Res. 2005; 40(5):395400.

13. Semalty A, Bhojwani M, Bhatt GK, Gupta GD, Shrivastav $A K$, Design and evaluation of mucoadhesive buccal films of diltiazem hydrochloride, Indian J Pharm Sci. 2005; 67(5):548552.

14. Semalty $M$, Semalty $A$, Kumar G. Formulation and characterization of mucoadhesive buccal films of glipizide, Indian J Pharm Sci. 2008; 70(1):4348.

15. Kim SE, Lee ER, Lee Y, Jeong M, Park YW, Ahn JS, Ahn $J T$, Seo K. A modified method for inducing periodontitis in dogs using a silk-wire twisted ligature. J Vet Sci. 2012; 13(2):193197.

16. Ionel A, Lucaciu O, Moga M, Buhatel D, Ilea A, Tabaran F, Catoi C, Berce C, Toader S, Campian RS. Periodontal disease induced in Wistar rats experimental study. HVM Bioflux 2015; 7(2):9095.

17. Liu DX, Ji XF, Song JT, Liu ZQ, and Hu B, Delivery of a calcium channel blocker through buccal mucosa from matrix type mucoadhesive films for improved cardiac drug delivery. J Biomater Tissue Eng. 2015; 5:586591.

18. Rusu D, Stratul SI, Sarbu C, Roman A, Anghel A, Didilescu A, Jentsch H. Evaluation of a hydrophobic gel adhering to the gingiva in comparison with a standard water-soluble $1 \%$ chlorhexidine gel after scaling and root planing in patients with moderate chronic periodontitis. A randomized clinical trial. Int J Dent Hyg. 2015, doi: 10.1111/idh. 12155.

19. Li MY, XuZT. The inhibition of dentifrice containing the lotus leaf-derived inhibitor on periodontitis-related bacteria in vitro. Int Dent J. 2007; 57(5):303306.

20. Bhatia $M$, Urolagin SS, Pentyala KB, Urolagin $S B, K B M$, Bhoi S. Novel therapeutic approach for the treatment of periodontitis by curcumin. J Clin Diagn Res. 2014; 8(12):6569.

21. Hosadurga RR, Rao $S N$, Edavanputhalath R, Jose J, Rompicharla NC, Shakil M, Raju S. Evaluation of the efficacy of $2 \%$ Ocimum sanctum gel in the treatment of experimental periodontitis. Int J Pharm Investig. 2015; 5(1):3542.

22. Gürkan $A$, Cinarcik $S$, Hüseyinov A. Adjunctive subantimicrobial dose doxycycline: effect on clinical parameters and gingival crevicular fluid transforming growth factor-beta levels in severe, generalized chronic periodontitis. J Clin Periodontol. 2005; 32(3):244253.

23. Mazzarino L, Borsali R, Lemos-Senna E. Mucoadhesive films containing chitosan-coated nanoparticles: a new strategy for buccal curcumin release. J Pharm Sci. 2014; 103(11):3764-3771.

24. Nagaraju R, Udupa $N$, Mathew J, Varma $B R$. Biodegradable dental implants of ciprofloxacin betacyclodextrin inclusion complex in the treatment of periodontitis. Indian J Exp Biol. 1999; 37(3):305307

25. Tözüm TF, Yildirim A, Cağlayan F, Dinçel A, Bozkurt A. Serum and gingival crevicular fluid levels of ciprofloxacin in patients with periodontitis. J Am Dent Assoc. 2004; 135(12):17281732

26. Nagaraju R, Udupa N. Biodegradable dental implants containing inclusion complexes of ciprofloxacin and norfloxacin with Indian Drugs 1998; 35(10):662665.

27. Ahmed MG, Harish NM, Charyulu RN, Prabhu $P$. Formulation of chitosan-based ciprofloxacin and diclofenac film for periodontitis therapy. Trop J Pharm Res. 2009; 8 (1):3339. 